\title{
EFFECT OF FLAVONE AND ITS MONOHYDROXY DERIVATIVES ON ANIMAL MODELS OF DEPRESSION IN SWISS ALBINO MICE
}

\author{
SHANMUGAPRIYAN S*, JAIKUMAR S, VISWANATHAN S, PARIMALA K, RAJESH M \\ Department of Pharmacology, Meenakshi Medical College and Research Institute, Meenakshi Academy of Higher Education and \\ Research,Kanchipuram, Tamil Nadu, India. Email: priyan.vellore.87@gmail.com
}

Received: 20 September 2018, Revised and Accepted: 07 November 2018

\section{ABSTRACT}

Objectives: This research was designed to investigate the antidepressant activity of a few structurally related flavones (flavone, 3-hydroxyflavone, and 7-hydroxyflavone) and the possible mechanisms involved.

Methods: Antidepressant activity was evaluated in mice by subjecting them to forced swim test and tail suspension test. The involvement of adrenergic, serotonergic, nitric oxide (NO), and opioid mechanisms was investigated using suitable interacting chemicals.

Results: Flavone, 3-hydroxyflavone, and 7-hydroxyflavone exhibited a significant and dose-dependent reduction in total time of immobility in the forced swim test and tail suspension test. Pre-treatment with alpha-methyl-para-tyrosine and parachlorophenyl alanine attenuated the reduction in immobility period produced by flavone and its derivatives in forced swim test. Naloxone pre-treatment partially reversed the effect of flavone while L-arginine pre-treatment did not alter their effect.

Conclusion: The investigated flavones exhibited promising antidepressant activity in both the animal models of depression. However, the flavone compounds did not alter the motor coordination and ambulatory behavior in the Rotarod and locomotor activity test. The participation of serotonergic, adrenergic, and opioid mechanism in the antidepressant activity of these compounds was elucidated from the results, and the role of NO pathway was excluded.

Keywords: Antidepressant activity, Flavone, Forced swim test, Tail suspension test.

(C) 2019 The Authors. Published by Innovare Academic Sciences Pvt Ltd. This is an open access article under the CC BY license (http://creativecommons. org/licenses/by/4. 0/) DOI: http://dx.doi.org/10.22159/ajpcr. 2019.v12i2.29856

\section{INTRODUCTION}

Depression is often under diagnosed and undertreated. The current antidepressant drugs such as monoamine oxidase inhibitors, selective serotonin reuptake inhibitors (SSRIs), tricyclic antidepressants, and inhibitors of norepinephrine and serotonin uptake delay the onset of resolution of depressive symptoms and cause serious adverse effects. An estimated $29-46 \%$ of patients treated for major depressive disorder have either a partial response or no response at all to antidepressive treatment. Hence, there is a continued need to search for an antidepressant drug which is more effective and safe [1]. Hypericum Perforatum, a European traditional medicine, has been extensively investigated and clinically evaluated in comparison with standard antidepressant drugs [2]. The medicinal plants are not only always free of side effects, for example, $H$. perforatum though exhibiting antidepressant-like actions, but also has some of its serious side effects [3]. Many plants used in the Indian traditional system of medicine have also been scientifically investigated for their effect in animal models of depression, and the mechanisms of action have also been explored [4]. This observation kindled an interest whether flavonoids could be a potential source for antidepressant drugs [5]. Flavonoids such as rutin [6], quercetin [7-9], and naringenin[10] that are widely distributed in many plants have been investigated for potential antidepressant effects. Most of the above compounds are polysubstituted flavones and it was considered interesting to explore the antidepressant activity of the basic flavone nucleus and its simpler derivatives. Hence, in this research, flavone and two of its mono-hydroxy derivatives have been investigated for considerable antidepressant effect in mice by subjecting them to forced swim test and tail suspension test. In addition, the possible mechanisms involved in the antidepressant effect of these compounds were also considered for investigation.

\section{METHODS}

Animals

For the current study, male adult Swiss albino mice weighing 25-30 g were selected and were sourced from the institutional animal house. On a natural day and night cycle, the animals were housed in a controlled environment with food and water available ad libitum. In all the experiments, each group consisted of six animals. Each animal was used only once. All the experiments were carried out between 9:00 and 13:00 h to avoid circadian variation and to maintain uniformity. The experimental protocol was approved by the Institutional Animal Ethics Committee (BR/HOS/85/2013/F-378 and KN/COL/3401/2014).

\section{Drugs and chemicals}

The compounds used in the study are flavone, 3-hydroxyflavone, and 7-hydroxyflavone, and its hydroxy derivatives were prepared as a fine suspension in $2 \%$ carboxymethyl cellulose and injected i.p. in doses of 5,10 , and $20 \mathrm{mg} / \mathrm{kg}, 30 \mathrm{~min}$ before the test procedures. The doses were selected based on the pilot study. Imipramine (Torrent Pharmaceuticals, India), para-chlorophenylalanine (PCPA) (Sigma-Aldrich, St. Louis, MO, USA), alpha-methyl-para-tyrosine (AMPT) (Sigma-Aldrich, St. Louis, MO, USA), naloxone hydrochloride (Endo Labs USA), L-arginine (Tokyo Chemical Industry, Japan), and diazepam (Neon Laboratories Ltd., Mumbai) were used in the present study.

\section{Ambulatory behavior by actophotometer test}

Mice were observed for ambulatory activity using an actophotometer (INCO, India). The activity of the animals was recorded by interruption of light beams passing through the square chambered apparatus. Mice were treated with flavone, 3-hydroxyflavone, or 7-hydroxyflavone in a dose of $20 \mathrm{mg} / \mathrm{kg}$ i.p. or vehicle and placed in the actophotometer after $30 \mathrm{~min}$. The number of beam breaks was 
recorded for 5 min [11]. The instrument was cleaned with cotton swab dipped in spirit in between the observations. Diazepam $(2 \mathrm{mg} / \mathrm{kg}$ i.p) was used for comparison in a separate group of mice.

\section{Motor coordination by Rotarod test}

The effect on motor coordination was evaluated by treating the mice with flavone, 3-hydroxyflavone, or 7-hydroxyflavone in a dose of $20 \mathrm{mg} / \mathrm{kg}$ i.p. or vehicle, $30 \mathrm{~min}$ before being tested on a Rotarod [12]. The apparatus (INCO, India) consists of a bar with a diameter of $2.5 \mathrm{~cm}$ subdivided into two compartments. The bar rotates at a constant speed of 15 revolutions/min and the ability of the animal to remain on the rotating rod (balancing time) was measured and compared with vehicle-treated animals. The cut-off time employed was $120 \mathrm{~s}$. A group of mice was treated with diazepam $2 \mathrm{mg} / \mathrm{kg}$ i.p. for comparison.

\section{Antidepressant activity by forced swim test ${ }^{[13]}$}

In this test, the mouse is forced to swim inside a vertical open cylindrical container (height $25 \mathrm{~cm}$ and diameter $10 \mathrm{~cm}$ ) with $19 \mathrm{~cm}$ of water (depth) and the temperature was maintained at $25 \pm 1^{\circ} \mathrm{C}$. Initially, the mouse swims vigorously in circles and tries to climb the wall or dive to the bottom. After a minute, the activity begins to subside and replaced with phases of immobility or floating of increasing length, with only minimal movements to keep its head above the water level. The total duration of immobility in seconds was recorded during a 6 -min period in which the $1^{\text {st }}$ min was given as the time for the animal to get adapted to the new environment. Hence, no readings were taken during the $1^{\text {st }} \mathrm{min}$. A decline in the duration of immobility is indicative of an antidepressant effect. Flavone, 3-hydroxyflavone, or 7-hydroxyflavone was administered i.p in doses of 5, 10, or $20 \mathrm{mg} / \mathrm{kg}$ to different groups of mice, $30 \mathrm{~min}$ before the test. Imipramine $20 \mathrm{mg} / \mathrm{kg}$ i.p was used for comparison in a separate group of mice. The doses of flavone compounds selected for the study were based on the pilot study conducted.

\section{Antidepressant activity by tail suspension test ${ }^{[14]}$}

In this method, a mouse is suspended in a rod of $10 \mathrm{~cm}$ length attached perpendicularly to the vertical iron stand, $50 \mathrm{~cm}$ above the floor by adhesive tape placed approximately $1 \mathrm{~cm}$ from the tip of the tail in a dim light and silent environment. The animal remains immobile after active and unsuccessful attempts to escape when suspended by tail. The animal was observed for $6 \mathrm{~min}$ and the immobility time was recorded. Effective antidepressants reduce the immobility time of the animals. Flavone, 3-hydroxyflavone, or 7-hydroxyflavone was injected i.p to different groups of mice in doses of 5, 10, or $20 \mathrm{mg} / \mathrm{kg}$. Animals were subjected to the test $30 \mathrm{~min}$ after administration of the test compounds. Imipramine $20 \mathrm{mg} / \mathrm{kg}$ i.p was used as a standard drug for comparison.

\section{Investigations on the mechanism of action}

Further, experiments were tried to elucidate the mechanisms by which flavone and its derivatives exerted their antidepressant activity. A single dose of flavone $(20 \mathrm{mg} / \mathrm{kg})$, 3-hydroxyflavone $(20 \mathrm{mg} / \mathrm{kg})$, or 7 -hydroxyflavone $(20 \mathrm{mg} / \mathrm{kg})$ was used for this purpose in the forced swim test in mice.

\section{Serotonergic system}

To assess the possible role of serotonergic system in the antidepressant effect of flavone and its derivatives, animals were pretreated with a 5-HT synthesis inhibitor, PCPA, $100 \mathrm{mg} / \mathrm{kg}$ i.p, for 4 consecutive days [6]. On the $5^{\text {th }}$ day, that is, $24 \mathrm{~h}$ after the last PCPA injection, the animals were given an injection of flavone or its derivatives in a dose of $20 \mathrm{mg} / \mathrm{kg}$ i.p and were employed to forced swim test after $30 \mathrm{~min}$.

\section{Adrenergic system}

To witness the contribution of adrenergic system, mice were pretreated with AMPT, an inhibitor of the enzyme tyrosine hydroxylase, $100 \mathrm{mg} / \mathrm{kg}$ i.p. [6]. After $4 \mathrm{~h}$, they received flavone or its hydroxy derivatives in a dose of $20 \mathrm{mg} / \mathrm{kg}$ i.p and were subjected to forced swim test, 30 min later.

\section{Opioid mechanism}

The participation of opioid system in the antidepressant action of flavone and its derivatives was investigated by pre-treating the mice with naloxone $5 \mathrm{mg} / \mathrm{kg}$ i.p [15], and after $15 \mathrm{~min}$, the animals received an injection of flavone or its derivatives in a dose of $20 \mathrm{mg} / \mathrm{kg}$ i.p. The antidepressant effect was recorded 30 min later using forced swim test.

\section{Nitric oxide (NO) mechanism}

Pre-treatment with L-arginine $(750 \mathrm{mg} / \mathrm{kg}$ i.p), a NO precursor, $15 \mathrm{~min}$ before flavone or its derivatives was attempted to investigate the role of NO pathway in the antidepressant effect of these compounds [16]. Flavone and its derivatives were used in a dose of $20 \mathrm{mg} / \mathrm{kg}$ i.p.

\section{Statistical analysis}

One-way ANOVA followed by Dunnett's t-test was used using SPSS 16 software to analyze the data obtained from various experiments. A probability value $<5 \%$ was considered to be statistically significant. Results are as mean \pm standard error mean

\section{RESULTS}

\section{Ambulatory behavior and motor coordination}

The balancing time of mice on a Rotarod and the activity score in the actophotometer were significantly reduced by diazepam $(2 \mathrm{mg} /$ $\mathrm{kg}$ i.p) treatment. Flavone and its hydroxy derivatives in a dose of $20 \mathrm{mg} / \mathrm{kg}$ i.p did not alter the activity score of mice in the actophotometer or the balancing time on the Rotarod apparatus when compared to vehicle-treated animals. Hence, the ambulatory behavior and motor coordination of mice were not significantly influenced by flavone and its hydroxy derivatives (Table 1).

\section{Forced swim test}

The immobility period recorded in vehicle-treated control animals was $195.07 \pm 5.8 \mathrm{~s}$. A significant reduction in immobility period was noted in imipramine $(20 \mathrm{mg} / \mathrm{kg})$-treated mice and the mean value was $3.47 \pm 1.49 \mathrm{~s}$. A dose proportionate reduction in immobility period compared to vehicle treatment was observed after treatment with different doses $(5,10$, and $20 \mathrm{mg} / \mathrm{kg}$ i.p) of flavone, 3-hydroxyflavone, and 7-hydroxyflavone. The percentage reduction in immobility period after treatment with different doses of the above test compounds was calculated in comparison with the vehicle treatment. The maximum reduction in immobility period in a dose of $20 \mathrm{mg} / \mathrm{kg}$ of flavone, 3-hydroxyflavone, and 7-hydroxyflavone was $88.49 \%, 45.48 \%$, and $55.88 \%$, respectively, while imipramine treatment produced $98 \%$ inhibition (Table 2).

\section{Tail suspension test}

The mean period of immobility in control group of animals was $206.85 \pm 5.76 \mathrm{~s}$ which was decreased to $14.84 \pm 1.41 \mathrm{~s}$ in imipramine $(20 \mathrm{mg} / \mathrm{kg})$-treated animals and the reduction was $92 \%$

Table 1: Effect of flavone and its monohydroxy derivatives on ambulatory behavior and motor performance of mice

\begin{tabular}{lll}
\hline Treatment groups (mg/kg i.p) & Activity score in the actophotometer (5 min) & Balancing time on the Rotarod (120 s) \\
\hline Vehicle & $464.33 \pm 9.34$ & $120.00 \pm 0.00$ \\
Diazepam (2) & $163.83 \pm 2.73^{\mathrm{a}}$ & $3.66 \pm 0.66^{\mathrm{a}}$ \\
Flavone (20) & $446.00 \pm 9.23$ & $120.00 \pm 0.00$ \\
3-hydroxyflavone (20) & $452.00 \pm 7.42$ & $120.00 \pm 0.00$ \\
7-hydroxyflavone (20) & $467.50 \pm 8.12$ & $120.00 \pm 0.00$ \\
\hline
\end{tabular}

${ }^{a} \mathrm{p}<0.05$ in comparison to vehicle (one-way ANOVA followed by Dunnett's t-test) 
when compared to vehicle-treated animals. A dose-dependent reduction in immobility period was observed in animals treated with increasing doses of flavone, 3-hydroxyflavone, and 7-hydroxyflavone (5, 10, and $20 \mathrm{mg} / \mathrm{kg}$ i.p). The percentage reduction in immobility period was calculated in comparison with the vehicle treatment. The maximum reduction in immobility period in a dose of $20 \mathrm{mg} / \mathrm{kg}$ of flavone, 3-hydroxyflavone, and 7-hydroxyflavone was $73.97 \%, 51.77 \%$ and $59.27 \%$, respectively (Table 3 ).

\section{Investigations on the mechanism of action \\ Involvement of serotonergic system}

Flavone, 3-hydroxyflavone, and 7-hydroxyflavones $(20 \mathrm{mg} / \mathrm{kg})$ per se significantly decreased the immobility time of mice in forced swim test compared with vehicle treatment. However, PCPA pre-treatment completely reversed the reduction in immobility period produced by the above compounds in forced swim test (Table 4).

\section{Involvement of adrenergic system}

Pre-treatment with AMPT did not significantly alter the period of immobility in vehicle-treated control animals. However, in AMPT-pretreated animals, the magnitude of reduction in immobility time due to flavone and its derivatives was significantly attenuated (Table 5).

\section{Involvement of opioid system}

Naloxone (5 mg/kg i.p) treatment per se did not significantly alter the immobility period of mice in forced swim test. However, a partial but significant reversal of the reduction of immobility period of mice was evident in animals treated with flavone and its derivatives (Table 6).

\section{Involvement of L-arginine-NO system}

L-arginine (750 mg/kg i.p) pre-treatment did not significantly modify the immobility period of vehicle-treated mice in forced swim test. The reduction in immobility period showed by flavone and its hydroxy derivatives was also not significantly modified by treatment with L-arginine (Table 7).

\section{DISCUSSION}

Mood and anxiety disorders are the most common psychiatric disorder widely presented to clinicians. Evidence are accruing that some natural products such as S-adenosine methionine, 1-methylfolate, and omega-3 fatty acids may be useful in depression [17]. Thus, there appear to be multiple novel targets for the new drug development to the treatment of depressive illness. It is pertinent to mention here that flavonoids are ubiquitous natural compounds endowed with many potential therapeutic benefits. Their opioid-like analgesic effect has been identified earlier [18]. A few recent studies have identified some flavone compounds such as rutin [6-9] and naringenin ${ }^{[10]}$ to be effective in animal models of depression. This research was undertaken to investigate the antidepressant activity of basic flavone nucleus and two of its monohydroxy derivatives.

The investigated compounds, such as flavone, 3-hydroxyflavone, and 7-hydroxyflavone, did not alter either the ambulatory activity or the balancing time of mice on a Rotarod. Assessment of motor coordination and ambulatory activity is essential because the important parameter monitored for antidepressant activity in both forced swim test and tail suspension test is the period of immobility. If the test compounds are going to affect the motor coordination and ambulatory activity, it may produce false positive/negative results [19]. The present results on flavone derivatives exclude such a possibility.

The results of the present study clearly depict that the time of immobility in the forced swim test as well as in the tail suspension test is decreased in a dose-dependent fashion in mice treated with flavone, 3-hydroxyflavone, or 7-hydroxyflavone (Tables 2 and 3). The reduction in immobility time was evidently significant even in a dose of $5 \mathrm{mg} / \mathrm{kg}$ of all the tested compounds in forced swim test. In the tail suspension test also, a similar trend has been observed except for 7-hydroxyflavone. The above findings clearly indicate an antidepressant-like effect of flavone, 3-hydroxyflavone, and 7-hydroxyflavone. It is important to point out that the antidepressant effect for these compounds was clearly evident even in a dose as low as $5 \mathrm{mg} / \mathrm{kg}$. Further, increase in doses augmented the antidepressant effect of these flavones as observed from the results of forced swim test and tail suspension test (Tables 2 and 3 ).

Mechanisms involved in the antidepressant effect of investigated flavones

It was considered interesting to investigate the possible mechanisms through which the antidepressant effects of flavones are mediated. The probable roles played by serotonergic, adrenergic, opioid, and NO pathways in the antidepressant effect of flavones have been investigated in the present study. PCPA, a tryptophan hydroxylase enzyme inhibitor when administered for 4 days in mice, is known to deplete the endogenous stores of serotonin by about $60 \%$ without altering the levels of noradrenaline and dopamine [20,21]. Pre-treatment with PCPA in

Table 2: Effect of flavone and its monohydroxy derivatives on mice in forced swim test

\begin{tabular}{llll}
\hline Dose (mg/kg i.p) & \multicolumn{3}{l}{ Period of immobility (s) } \\
\cline { 2 - 4 } & Flavone & 3-hydroxyflavone & 7-hydroxyflavone \\
\hline Vehicle & $195.07 \pm 5.8$ & $195.07 \pm 5.8$ & $195.07 \pm 5.8$ \\
Imipramine (\%) & $3.47 \pm 1.49(98)$ & $3.47 \pm 1.49(98)$ & $3.47 \pm 1.49(98)$ \\
$5 \mathrm{mg} / \mathrm{kg}$ & $138.86 \pm 2.68^{\mathrm{a}}(40.42)$ & $157.69 \pm 1.78^{\mathrm{a}}(19.16)$ & $171.80 \pm 4.23^{\mathrm{a}}(11.92)$ \\
$10 \mathrm{mg} / \mathrm{kg}$ & $119.40 \pm 1.77^{\mathrm{a}}(38.79)$ & $137.48 \pm 8.7^{\mathrm{a}}(29.52)$ & $111.16 \pm 4.69^{\mathrm{a}}(43.01)$ \\
$20 \mathrm{mg} / \mathrm{kg}$ & $22.45 \pm 3.85^{\mathrm{a}}(88.49)$ & $106.34 \pm 6.03^{\mathrm{a}}(45.48)$ & $86.05 \pm 2.14^{\mathrm{a}}(55.88)$ \\
\hline
\end{tabular}

${ }^{\mathrm{a}} \mathrm{p}<0.05$ in comparison to vehicle (one-way ANOVA followed by Dunnett's t-test). The values in brackets indicate the percentage reduction of immobility duration compared to vehicle

Table 3: Effect of flavone and its monohydroxy derivatives on mice in tail suspension test

\begin{tabular}{llll}
\hline Dose mg/kg i.p & Period of immobility (s) & \\
\cline { 2 - 4 } & Flavone & 3-hydroxyflavone & 7-hydroxyflavone \\
\hline Vehicle & $206.85 \pm 5.76$ & $206.85 \pm 5.76$ & $206.85 \pm 5.76$ \\
Imipramine (\%) & $14.84 \pm 1.41(92)$ & $14.84 \pm 1.41(92)$ & $14.84 \pm 1.41(92)$ \\
$5 \mathrm{mg} / \mathrm{kg}$ & $171.52 \pm 3.83^{\mathrm{a}}(17.08)$ & $197.15 \pm 1.56(4.68)$ & $174.18 \pm 2.66^{\mathrm{a}}(15.79)$ \\
$10 \mathrm{mg} / \mathrm{kg}$ & $154.75 \pm 5.81^{\mathrm{a}}(25.18)$ & $184.57 \pm 7.67^{\mathrm{a}}(10.77)$ & $140.13 \pm 2.97^{\mathrm{a}}(32.25)$ \\
$20 \mathrm{mg} / \mathrm{kg}$ & $53.84 \pm 4.85^{\mathrm{a}}(73.97)$ & $99.76 \pm 7.68^{\mathrm{a}}(51.77)$ & $84.23 \pm 4.14^{\mathrm{a}}(59.27)$ \\
\hline
\end{tabular}

${ }^{a} \mathrm{p}<0.05$ in comparison to vehicle (one-way ANOVA followed by Dunnett's t-test). The values in brackets indicate the percentage reduction of immobility duration compared to vehicle 
Table 4: Effect of PCPA pre-treatment on flavone and its monohydroxy derivatives on mice in forced swim test

\begin{tabular}{lll}
\hline Treatment (mg/kg i.p) & $\begin{array}{l}\text { Immobility } \\
\text { period (s) } \\
\text { without PCPA }\end{array}$ & $\begin{array}{l}\text { Immobility } \\
\text { period (s) with } \\
\text { PCPA }\end{array}$ \\
\hline Vehicle & $195.07 \pm 5.8$ & $205.92 \pm 5.35$ \\
Flavone (20) & $22.45 \pm 3.85^{\mathrm{a}}$ & $156.05 \pm 1.64^{\mathrm{b}}$ \\
3-hydroxyflavone (20) & $106.34 \pm 6.03^{\mathrm{a}}$ & $192.43 \pm 1.80^{\mathrm{b}}$ \\
7-hydroxyflavone (20) & $86.05 \pm 2.14^{\mathrm{a}}$ & $201.48 \pm 0.43^{\mathrm{b}}$ \\
\hline
\end{tabular}

${ }^{a} \mathrm{p}<0.05$ in comparison to vehicle (one-way ANOVA followed by Dunnett's t-test), ${ }^{\mathrm{b}} \mathrm{p}<0.05$ compared to PCPA $100 \mathrm{mg} / \mathrm{kg}$ i.p pre-treated animals (one-way ANOVA followed by Dunnett's t-test). PCPA: Parachlorophenylalanine

Table 5: Effect of AMPT pre-treatment on flavone and its monohydroxy derivatives on mice in forced swim test

\begin{tabular}{lll}
\hline Treatment (mg/kg i.p) & $\begin{array}{l}\text { Immobility } \\
\text { time (s) without } \\
\text { AMPT }\end{array}$ & $\begin{array}{l}\text { Immobility } \\
\text { time (s) with } \\
\text { AMPT }\end{array}$ \\
\hline Vehicle & $195.07 \pm 5.8$ & $205.92 \pm 5.35$ \\
Flavone (20) & $22.45 \pm 3.85^{\mathrm{a}}$ & $156.05 \pm 1.64^{\mathrm{b}}$ \\
3-hydroxyflavone (20) & $106.34 \pm 6.03^{\mathrm{a}}$ & $192.43 \pm 1.80^{\mathrm{b}}$ \\
7-hydroxyflavone (20) & $86.05 \pm 2.14^{\mathrm{a}}$ & $201.48 \pm 0.43^{\mathrm{b}}$ \\
\hline${ }^{\mathrm{a}} \mathrm{p}<0.05$ in comparison to vehicle (one-way ANOVA followed by Dunnett's t-test). \\
${ }^{\mathrm{b}}$ p<0.05 compared to AMPT-pretreated animals 100 mg/kg i.p (one-way ANOVA \\
followed by Dunnett's t-test). AMPT: Alpha-methyl-para-tyrosine
\end{tabular}

Table 6: Effect of naloxone pre-treatment on flavone and its monohydroxy derivatives on mice in forced swim test

\begin{tabular}{lll}
\hline Treatment (mg/kg i.p) & $\begin{array}{l}\text { Immobility } \\
\text { time (s) without } \\
\text { naloxone }\end{array}$ & $\begin{array}{l}\text { Immobility } \\
\text { time (s) with } \\
\text { naloxone }\end{array}$ \\
\hline Vehicle & $195.07 \pm 5.8$ & $196.95 \pm 0.97$ \\
Flavone (20) & $22.45 \pm 3.85^{\mathrm{a}}$ & $35.10 \pm 2.33^{\mathrm{b}}$ \\
3-hydroxyflavone (20) & $106.34 \pm 6.03^{\mathrm{a}}$ & $136.73 \pm 3.99^{\mathrm{b}}$ \\
7-hydroxyflavone (20) & $86.05 \pm 2.14^{\mathrm{a}}$ & $117.11 \pm 2.43^{\mathrm{b}}$ \\
\hline${ }^{\mathrm{a}}$ p<0.05 in comparison to vehicle (one-way ANOVA followed by Dunnett's \\
t-test). ${ }^{\mathrm{b}}$ <<0.05 compared to naloxone pretreated animals 5 mg/kg i.p (one-way \\
ANOVA followed by Dunnett's t-test)
\end{tabular}

Table 7: Effect of L-arginine pre-treatment on flavone and its monohydroxy derivatives on mice in forced swim test

\begin{tabular}{lll}
\hline Treatment (mg/kg i.p) & $\begin{array}{l}\text { Immobility } \\
\text { time (s) without } \\
\text { L-arginine }\end{array}$ & $\begin{array}{l}\text { Immobility } \\
\text { time (s) with } \\
\text { L-arginine }\end{array}$ \\
\hline Vehicle & $195.07 \pm 5.8$ & $200.57 \pm 2.93$ \\
Flavone (20) & $22.45 \pm 3.85^{\mathrm{a}}$ & $25.67 \pm 0.68$ \\
3-hydroxyflavone (20) & $106.34 \pm 6.03^{\mathrm{a}}$ & $110.29 \pm 2.05$ \\
7-hydroxyflavone (20) & $86.05 \pm 2.14^{\mathrm{a}}$ & $79.32 \pm 3.18$ \\
\hline ap<0.05 compared to vehicle (one-
\end{tabular}

${ }^{\mathrm{a}} \mathrm{p}<0.05$ compared to vehicle (one-way ANOVA followed by Dunnett's t-test)

mice has been shown to alter the response to SSRIs such as fluoxetine and citalopram [22]. The results of the present research indicate that PCPA pre-treatment effectively reversed the reduction in immobility period produced by flavone, 3-hydroxyflavone, and 7-hydroxyflavone in the forced swim test (Table 4). This observation clearly indicates the role of serotonergic mechanisms in the antidepressant effect of all the three investigated flavones. Flavonoids such as rutin [6], vitexin [23], liquiritin, and isoliquiritin ${ }^{[2]}$ and flavonoids from $H$. perforatum ${ }^{[2]}$ have been earlier shown to involve serotonergic pathways in mediating their antidepressant effect. The present result is in agreement with these findings, and serotonergic mechanism may be considered as an important mode of action in the antidepressant effect of flavonoids in general.
The role of adrenergic system in the effect of antidepressant drugs is generally studied by employing tyrosine hydroxylase inhibitor AMPT, which has been shown to reduce the levels of dopamine and nonadrenaline to an extent of 57 and 53\%, respectively, in mice without altering the levels of serotonin [25]. The results of the present study indicate that prior administration of AMPT significantly reversed the decrease in immobility period of mice produced by flavone, 3-hydroxyflavone, and 7-hydroxyflavone treatment in forced swim test (Table 5). This observation shows the valid role for adrenergic system in the antidepressant effect of the above flavones. Previous studies on flavonoids such as rutin 4, liquiritin and isoliquiritiin [24], and vitexin ${ }^{[23]}$ and flavonoids from $H$. perforatum ${ }^{[2]}$ indicated an involvement of adrenergic mechanism in their antidepressant effect. The present results on flavone and its monohydroxy derivatives are in agreement with the earlier reports.

The $\mu$-opioid receptors are implicated in depression and stress states due to their dense distribution in brain areas associated with stress and emotion. Serum $\beta$-endorphin levels have been shown to be decreased in patients with severe depression [26,27]. Amentoflavone and hyperoside present in $H$. perforatum have $\kappa$ antagonist activity in vitro, and Katavic also suggested flavonoid core as a future new scaffold for the development of opioid receptor ligands [28]. Moreover, central administration of endogenous peptides such as endomorphin-1 and endomorphin- 2 has been shown to possess antidepressant activity in mice [15]. All these evidence indicate a prominent role for opioid system in the development of depression. Flavone and many of its hydroxy derivatives were found to possess opioid-mediated analgesic action in mice. Hence, it was considered interesting to investigate the possible participation of opioid mechanism in the antidepressant effect of the investigated flavones. Naloxone, a non-specific opioid antagonist, was used for this purpose. It is clear from the results (Table 6) that naloxone administration partially reversed the reduction in immobility period produced by flavone, 3-hydroxyflavone, and 7-hydroxyflavone. There is no complete suppression of the effect of flavones with naloxone pre-treatment. The results, thus, depict that the antidepressant effect of the investigated flavones at least in part could be due to the involvement of opioid mechanism.

The participation of L-arginine-NO pathway in the modulation of depression has been reported earlier by Da Silva et al. [29]. Melatonin has been shown to exert an antidepressant effect through an interaction with NMDA receptors and L-arginine-NO pathway [15]. A flavanone glycoside hesperidin exhibited antidepressant activity involving NO -GMP pathway [30]. These authors provided evidence that NO donor L-arginine could attenuate the antidepressant effect of hesperidin. A recent report identified the role of NO modulatory mechanism in the neuroprotective effect of rutin, and L-arginine pre-treatment has been shown to significantly reverse the protective effect of rutin against immobilization stress-induced anxiety-like behavior [31]. In light of aforementioned information, it was considered interesting to investigate the role of NO in the antidepressant effect of flavones. A NO donor L-arginine was employed for this purpose [32]. However, pre-treatment with L-arginine did not significantly modify the reduction in immobility period affected by flavone, 3-hydroxyflavone, or 7-hydroxyflavone. The unaltered response of the above flavones in the presence of L-arginine indicates that NO mechanism may not play a role in the antidepressant effect of these compounds.

\section{CONCLUSION}

The present study has identified the novel antidepressant activity of the basic flavone scaffold and its monohydroxy derivatives. The major participation of serotonergic and adrenergic mechanisms and partial role of opioid mechanism in the antidepressant effect of flavone compounds were also revealed. Since multiple neurotransmitter systems are involved in the antidepressant effect of the flavone compounds, the serious side effects are inevitable. Hence, the safety profile of the compound needs to be evaluated. 


\section{ACKNOWLEDGMENT}

Authors are thankful to Dr. Chandran, veterinarian, and Mrs. Sharmaila for their technical support.

\section{AUTHORS' CONTRIBUTIONS}

Dr. Shanmugapriyan S performed the study and collected the data. Dr. Viswanathan $\mathrm{S}$ designed the analysis. Dr. Jaikumar S and Dr. Parimala K performed the analysis. Dr. Shanmugapriyan S and Dr. Rajesh M wrote the manuscript.

\section{CONFLICTS OF INTEREST}

Authors declare that they have no conflicts of interest.

\section{REFERENCES}

1. Dattatray BP, Padmaja AM, Nirmala NR. Antidepressant activity of aqueous extracts of fruits of Terminalia chebula and Phyllanthus emblica in behavioural models of depression: Involvement of monoaminergic system. Int J Pharm Pharm Sci 2014;6:615-20.

2. Nathan PJ. Hypericum perforatum (St john's wort): A non-selective reuptake inhibitor? A review of the recent advances in its pharmacology. J Psychopharmacol 2001;15:47-54.

3. Rodríguez-Landa JF, Contreras CM. A review of clinical and experimental observations about antidepressant actions and side effects produced by Hypericum perforatum extracts. Phytomedicine 2003;10:688-99

4. Arya A, Verma P. An emerging role of herbal therapy in depression. Int J Drug Discov Herbal Res 2012;2012:282-95.

5. German-Ponciano LJ, Rosas-Sánchez GU, Rivadeneyra-Domínguez E, Rodríguez-Landa JF. Advances in the preclinical study of some flavonoids as potential antidepressant agents. Scientifica (Cairo) 2018;2018:2963565.

6. Machado DG, Bettio LE, Cunha MP, Santos AR, Pizzolatti MG, Brighente IM, et al. Antidepressant-like effect of rutin isolated from the ethanolic extract from Schinus molle L. In mice: Evidence for the involvement of the serotonergic and noradrenergic systems. Eur J Pharmacol 2008;587:163-8.

7. Lu YH, Du CB, Liu JW, Hong W, Wei DZ. Neuroprotective effects of Hypericum perforatum on trauma induced by hydrogen peroxide in PC12 cells. Am J Chin Med 2004;32:397-405.

8. Borrelli F, Izzo AA. Herb-drug interactions with st john's wort (Hypericum perforatum): An update on clinical observations. AAPS J 2009;11:710-27.

9. Kawabata, K, Kawai, Y, Terao, J. Suppressive effect of quercetin on acute stress-induced hypothalamic-pituitary-adrenal axis response in wistar rats. J Nutr Biochem 2010;21:374-80.

10. Yi LT, Li CF, Zhan X, Cui CC, Xiao F, Zhou LP, et al. Involvement of monoaminergic system in the antidepressant-like effect of the flavonoid Naringenin in mice. Prog Neuropsychopharmacol Biol Psychiatry 2010;34:1223-8.

11. Mahendran G, Thamotharan G, Sengottuvelu S, Bai VN. Evaluation of anticonvulsant, sedative, anxiolytic, and phytochemical profile of the methanol extract from the aerial parts of Swertia corymbosa (Griseb.) wight ex C.B. Clarke. Biomed Res Int 2014;2014:542385.

12. Jürgensen S, Dalbó S, Angers P, Santos AR, Ribeiro-do-Valle RM. Involvement of 5-HT2 receptors in the antinociceptive effect of Uncaria tomentosa. Pharmacol Biochem Behav 2005;81:466-77.

13. Porsolt RD, Bertin A, Jalfre M. Behavioural despair in rats and mice: Strain differences and the effects of imipramine. Eur J Pharm 1978;51:291-4.

14. Steru L, Chermat R, Thierry B, Simon P. The tail suspension test: A new method for screening antidepressants in mice. Psychopharmacology (Berl) 1985;85:367-70.

15. Fichna J, Janecka A, Costentin J, Do Rego JC. The endomorphin system and its evolving neurophysiological role. Pharmacol Rev 2007;59:88-123.

16. Mantovani M, Pértile R, Calixto JB, Santos AR, Rodrigues AL. Melatonin exerts an antidepressant-like effect in the tail suspension test in mice: Evidence for involvement of N-methyl-D-aspartate receptors and the L-arginine-nitric oxide pathway. Neurosci Lett 2003;343:1-4.

17. O'Donnell JM, Shelton RC. Drug therapy of depression and anxiety disorders. In: Goodman and Gillman's-The Pharmacological Basis of Therapeutics. $12^{\text {th }}$ ed. New Delhi: McGraw Hill; 2011. p. 397-415.

18. Viswanathan S, Sambantham PT, Reddy K, Kameswaran L. Gossypin-induced analgesia in mice. Eur J Pharmacol 1984;98:289-91.

19. Bogdanova OV, Kanekar S, D'Anci KE, Renshaw PF. Factors influencing behavior in the forced swim test. Physiol Behav 2013;118:227-39.

20. Redrobe JP, Bourin M, Colombel MC, Baker GB. Psychopharmacological profile of the selective serotonin reuptake inhibitor, paroxetine: Implication of noradrenergic and serotonergic mechanisms. J Psychopharmacol 1998;12:348-55.

21. Redrobe JP, Bourin M. Evidence of the activity of lithium on 5-HT1B receptors in the mouse forced swimming test: Comparison with carbamazepine and sodium valproate. Psychopharmacology (Berl) 1999; $141: 370-7$

22. O'Leary OF, Bechtholt AJ, Crowley JJ, Hill TE, Page ME, Lucki I, et al. Depletion of serotonin and catecholamines block the acute behavioral response to different classes of antidepressant drugs in the mouse tail suspension test. Psychopharmacology (Berl) 2007;192:357-71.

23. Can ÖD, Demir Özkay Ü, Üçel Uİ. Anti-depressant-like effect of vitexin in $\mathrm{BALB} / \mathrm{c}$ mice and evidence for the involvement of monoaminergic mechanisms. Eur J Pharmacol 2013;699:250-7.

24. Wang X, Zhang L, Hua L, Xing D, Du L. Effect of Flavonoids in Scutellariae radix on depression-like behaviour and brain rewards: Possible in dopamine system. Tsinghua Sci Technol 2010;15:460-6.

25. Mayorga AJ, Dalvi A, Page ME, Zimov-Levinson S, Hen R, Lucki I, et al. Antidepressant-like behavioral effects in 5-hydroxytryptamine (1A) and 5-hydroxytryptamine (1B) receptor mutant mice. J Pharmacol Exp Ther 2001;298:1101-7.

26. Darko DF, Risch SC, Gillin JC, Golshan S. Association of beta-endorphin with specific clinical symptoms of depression. Am J Psychiatry 1992;149:1162-7.

27. Djurović D, Milić-Askrabić J, Majkić-Singh N. Serum beta-endorphin level in patients with depression on fluvoxamine. Farmaco 1999;54:130-3.

28. Paramdeep S, Damanpreet S, Rajesh KG. Phytoflavonoids: Antiepileptics for the future. Int J Pharm Pharm Sci 2014;6:51-66.

29. da Silva GD, Matteussi AS, dos Santos AR, Calixto JB, Rodrigues AL. Evidence for dual effects of nitric oxide in the forced swimming test and in the tail suspension test in mice. Neuroreport 2000;11:3699-702.

30. Yildiz F, Erden BF, Ulak G, Utkan T, Gacar N. Antidepressant-like effect of 7-nitroindazole in the forced swimming test in rats. Psychopharmacology (Berl) 2000;149:41-4.

31. Donato F, de Gomes MG, Goes AT, Filho CB, Del Fabbro L, Antunes MS, et al. Hesperidin exerts antidepressant-like effects in acute and chronic treatments in mice: Possible role of 1-arginine-NO-cGMP pathway and BDNF levels. Brain Res Bull 2014;104:19-26.

32. Machawal L, Kumar A. Possible involvement of nitric oxide mechanism in the neuroprotective effect of rutin against immobilization stress induced anxiety like behaviour, oxidative damage in mice. Pharmacol Rep 2014;66:15-21. 